\title{
Influenza-Associated Myositis in Children
}

\author{
P. Agyeman, A. Duppenthaler, U. Heininger, C. Aebi
}

\begin{abstract}
Background: Influenza-associated myositis (IAM) is an infrequent and poorly known complication of influenza virus infection in children. The aim of this study was to describe five cases of IAM and to review the literature on IAM in children.

Patients and Methods: We conducted a retrospective analysis of cases of IAM diagnosed at two university children's hospitals in Switzerland during two consecutive influenza seasons. Findings were compared with 39 individual case reports and five publications summarizing an additional 272 cases identified by a medical online library (MEDLINE) search.

Results: Overall, 316 cases were analyzed. IAM typically occurred in school-aged children with a 2:1 male predominance. Influenza $B$ and A viruses were identified in $76 \%$ and $24 \%$ of cases, respectively. The median interval between onset of influenza and onset of IAM was 3 days (range $0-18$ ). The calf muscles were involved alone or together with other muscle groups in $69 \%$ and $31 \%$ of cases, respectively. Blood creatine phosphokinase (CPK)

concentration was invariably elevated. Median duration to clinical recovery was 3 days (range 1-30). Rhabdomyolysis occurred in ten of 316 patients $(3 \%)$, was more common in girls $(80 \%)$, more often associated with influenza A (86\%), and led to renal failure in eight patients (80\%).

Conclusion: Clinical and laboratory findings of IAM are highly characteristic and allow a rapid diagnosis during the influenza season.
\end{abstract}

Infection 2004; 32: 199-203

DOI 10.1007/s15010-004-4003-2

\section{Introduction}

Influenza is a common and usually benign viral respiratory tract infection occurring worldwide in annual epidemics during the cold season. According to established medical knowledge, complications are mainly seen in the elderly. Recent studies, however, indicate that influenza-associated morbidity in children may be greater than previously thought $[1,2]$. Complications mainly affect the respiratory tract and the central nervous system. Another complication of influenza, which has only sporadically been reported since its first description in 1957 [3], is influenza-associated myositis (IAM). IAM appears to be more common in children than in adults, but its age-specific incidence during influenza epidemics is unknown. As IAM has typically been associated with the influenza B virus, its incidence may depend on the nature of circulating strains during a given epidemic.

There is no standardized nomenclature of IAM in the literature and the pathogenetic events leading to muscle involvement have not been elucidated in detail. Nevertheless, both the clinical presentation and laboratory characteristics of IAM seem fairly typical. Clinical manifestations can be dramatic and IAM often causes diagnostic confusion because it is a poorly known entity in the medical community. Although IAM usually follows a benign and self-limiting course, several cases with a severe course and life-threatening complications have been reported.

The aim of this study was to review recent experiences with IAM at two large pediatric hospitals in Switzerland and to review the medical literature.

\section{Patients and Methods Definitions}

IAM was defined as follows: Virologically proven influenza or influenza-like illness plus clinical evidence for localized myalgia plus elevation of serum creatine phosphokinase (CPK) or abnormal muscle biopsy in a patient younger than 16 years of age. The term "rhabdomyolysis" was reserved arbitrarily for patients who also had myoglobinuria.

\footnotetext{
P. Agyeman, A. Duppenthaler, C. Aebi (corresponding author) Dept. of Pediatrics and Institute of Infectious Diseases, University of Bern, CH-3010 Bern, Switzerland; Phone: (+41/31) 632-9487; Fax: -9468, e-mail: christoph.aebi@insel.ch U. Heininger

University Children's Hospital, University of Basel, Switzerland
} 


\section{Patients}

Medical records from children with IAM, who were seen at the University Children's Hospitals of Bern or Basel, Switzerland, during the influenza seasons in 2002 and 2003, were analyzed. The following set of clinical data was retrieved for each patient: age, gender, reason for referral, duration and characteristics of influenza or influenza-like illness, muscle symptoms, other symptoms and signs, laboratory parameters at presentation (i.e. peripheral white blood cell count, serum C-reactive protein, CPK, aspartate transaminase (ASAT), alanine transaminase (ALAT), creatinine, and urinalysis), duration and course of illness, and outcome.

\section{Laboratory Detection of Influenza Virus}

Nasopharyngeal secretions (NPS) were sampled using a Vygon infant mucus aspirator (Ecouen, France) and assessed for the presence of influenza A and B using a direct immunofluorescence assay (Light Diagnostics Respiratory Panel DFA, Chemicon International, Inc., Temecula, CA, USA) or by a multiplex polymerase chain reaction (PCR). This method was designed to amplify cDNA specific for influenza $A$ and $B$, respiratory syncytial virus (RSV), parainfluenza virus types 1 and 3, and adenovirus. Viral RNA was purified from NPS by use of the QIAamp Viral RNA kit (Qiagen, Basel, Switzerland), and cDNA was synthesized by means of reverse transcriptase PCR (Titan One Tube RT-PCR System, Roche, Basel, Switzerland). Multiplex PCR was performed in two separate assays. One assay contained specific primers for influenza A, influenza B, and parainfluenza virus type 1 . Amplification products were sequenced.

\section{Review of the Literature}

A medical online library (MEDLINE) search using the keywords influenza and muscle or myositis or rhabdomyolysis was performed. Additional reports were retrieved using the reference lists of papers identified by MEDLINE. Reports written in English, French and German were considered. In 39 cases of IAM, case descriptions provided sufficient detail to allow entry into the database. This group of cases was named the reference group and was compared to large case series which lacked individual patient data.

\section{Results}

Our Cases

We identified five patients with IAM (Table 1). Private pediatricians referred four patients, one patient with severe calf pain presented to the emergency room. In four patients, the reason for referral was incapacitating calf pain. Suspected diagnoses were Guillain-Barré syndrome in three patients, deep venous thrombosis in one, and cerebellar ataxia in one. The median age was 8.3 years (range 7.3-10.3). All patients had a history of a recent influenzalike illness starting 2 to 5 days before presentation and consisting of fever and rhinorrhea. Additional complaints were sore throat, nausea, cough, and headache in patient 1 , cough in patient 2 , and headache and dizziness in patient 4 . In patients referred by their private physician, muscle symptoms had started 1 to 2 days before presentation. Patient 3 presented on the day myalgia had started. The median interval between the onset of influenza and the onset of muscle symptoms was 2.5 days (range $0-4$ ).
During clinical examination, all patients were afebrile, had normal vital signs, and appeared non-toxic. No influenza-associated respiratory signs were present in patients 3 and 4. Rhinitis was observed in patients 1,2 and 5 . Pharyngitis was observed in patient 1 . The predominant clinical manifestation in all patients was severe pain and localized tenderness of the calf muscles bilaterally, which led to abnormal gait or refusal to walk. Neurologic examination was normal. There was no gross hematuria. IAM was suspected in all patients and confirmation was achieved by demonstrating massively elevated serum CPK concentrations. Myoglobinuria was found in patient 4. Influenza virus infection was documented in four patients by demonstration of influenza A or B virus in NPS. Two patients were hospitalized briefly. All patients had a favorable outcome. No complications or sequelae were recorded.

\section{Review of the Literature}

We identified 311 cases of IAM [3-36]. Ten patients had recurrent episodes $[3,4,17,18,34]$. Of 294 patients in whom the gender was noted, 200 were male, resulting in a gender ratio of 2:1. Detailed data were available from the reference group consisting of 39 patients (Table 2). The median age was 8.5 years (range 2.5-14). Lundberg [3] reported a median age of 9 years, Mackay et al. [34] and Farrell et al. [17] found a mean age of 8.1 and 7 years, respectively. In the reference group, the median interval between the onset of influenza-associated symptoms and the onset of muscle symptoms was 3 days (range 0-18). Lundberg [3], Mackay et al. [34] and Farrell et al. [17] found a median interval of 2.6, 5 and 5 days, respectively. In the reference group the most frequent influenza-associated symptom was fever (74\%), followed by cough (33\%), rhinorrhea (26\%), nausea and vomiting (23\% each). Lundberg [3] recorded fever in $92 \%$, headache in $80 \%$, and rhinitis and cough in $49 \%$ and $46 \%$, respectively. Nausea and vomiting were present in $41 \%$. In the reference group, muscle pain was located exclusively in the lower extremities in $69 \%$, particularly in the calf muscles. Involvement of the upper extremities occurred in $20 \%$ of cases and was always accompanied by lower extremity involvement. Four patients $(10 \%)$ experienced generalized myalgia and in two cases (5\%) paraspinal muscles were involved $[16,25]$. Refusal to walk and gait abnormalities occurred in ten (26\%) and 11 (28\%) patients, respectively. Clinical examination revealed tenderness of affected muscles $(74 \%)$ as the most frequent finding besides muscle pain. Soft tissue edema was present in five children $(13 \%)$. Mackay et al. [34] found refusal to walk in 19\%, with the remaining $81 \%$ showing gait abnormalities. In the reference group, the duration of muscle symptoms ranged from 1 to 30 days (median 3 days). Lundberg [3] and Middleton et al. [4] reported a mean duration of 3 days. Farrell et al. [17] noted that recovery took 3 to five days. CPK was determined in 36 patients listed in the reference group (median 4,100 U/l; range 230->106). Overall, CPK was measured in 230 of 311 cases and was elevated in 219 (95\%). Serum lac- 
tic dehydrogenase (LDH) and aspartate transaminase (AST) were also frequently elevated. Virologic analyses performed in 190 cases yielded influenza B in 100 cases, influenza $\mathrm{A}$ in 31 , and other viruses in 11 . In one child, the type of influenza virus was not specified. In 47 cases the result was negative.

Clinical course and outcome were mostly benign, but ten of 311 reported children (3\%) developed severe rhabdomyolysis $[9,14,23,25,27,31-33,36]$. The median age was 9.3 years (range $3-14$ ). In contrast to uncomplicated cases of IAM, which had a male predominance of 2:1 and usually affected the lower extremities, influenza-associated rhabdomyolysis occurred more often in girls (4:1), and pain and tenderness were mostly diffuse. Gross hematuria and myoglobinuria were recorded in five and nine patients, respectively. Viral studies were performed in seven cases (influenza A in six cases, influenza B in one). Eight patients had acute renal failure $[9,23,27,31-33,36]$. This condition resolved completely in all but one patient [23], but intensive care management with temporary dialysis was necessary in six cases. Two patients $[27,36]$ suffered from compartment syndrome and underwent fasciotomy, which left one patient with a permanent walking disability. Two patients $[9,36]$ required artificial ventilation. One patient [23] with familial carnitine palmitoyl-transferase deficiency died.

\section{Discussion}

The first description of IAM as a clinically distinct entity dates from 1957, when Lundberg [3] reported 70 children and four adults with what he called "myalgia cruris epidemica." This report has remained the largest collection of cases of IAM in the literature. Lundberg postulated a viral etiology based on clinical and epidemiologic data, but neither virologic analyses, nor blood CPK determinations were performed. Middleton et al. [4] were the first to provide laboratory evidence in support of an association with influenza virus infection, which was demonstrated in 21 of 26 cases described. Elevated CPK levels were found in 14 of 21 virologicaly confirmed cases.

Since then, cases with similar clinical and laboratory findings were reported from different parts of the world. The muscle affection was mostly named myositis, although it is still unclear whether an inflammatory infiltrate justifying the term myositis is usually present. Blood CPK is almost invariably elevated and indicates muscle damage, but biopsy results are rarely compatible with frank myositis. The largest series of biopsies in children with IAM was presented by Bove et al. [37]. Eleven of 12 biopsy specimens showed patchy necrosis with little inflammatory infiltration, and one specimen showed no changes at all. Overall, we identified 35 reports of muscle biopsies in children with IAM. Of these, 28 specimens [ $5,8,14,17,18,23,34,36,37]$ had shown evidence of muscle degeneration and necrosis. Inflammatory infiltrates were found in five specimens only $[5,14,18,37]$. Six specimens $[3,9,12,16,37]$ showed no or

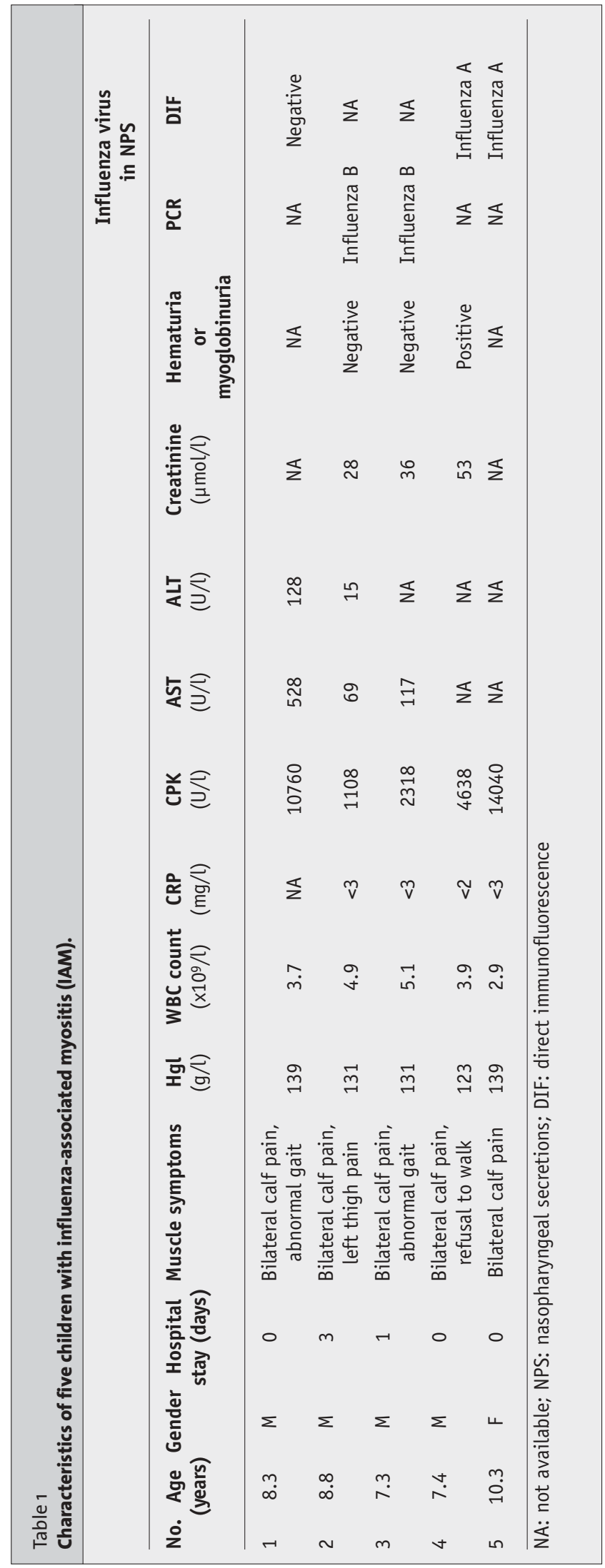




\begin{tabular}{|c|c|c|}
\hline Parameter & Value & $\begin{array}{l}\text { No. of patients } \\
\text { with data } \\
\text { available }\end{array}$ \\
\hline Median age (years) [range] & $8.5[2.5-14]$ & 39 \\
\hline Male gender $(\%)$ & $26(67)$ & 39 \\
\hline Median interval (days) [range] ${ }^{a}$ & $3[0-18]$ & 30 \\
\hline \multicolumn{3}{|c|}{ Location of muscle pain } \\
\hline Lower extremities (\%) & $27(69)$ & 39 \\
\hline $\begin{array}{l}\text { Lower and upper } \\
\text { extremities (\%) }\end{array}$ & $8(20)$ & 39 \\
\hline Generalized (\%) & $4(10)$ & 39 \\
\hline $\begin{array}{l}\text { Median creatine } \\
\text { phosphokinase (U/L) [range] }\end{array}$ & $\begin{array}{l}4,100[230- \\
1,000,000]\end{array}$ & 36 \\
\hline \multicolumn{3}{|l|}{$\begin{array}{l}\text { Detection of influenza } \\
\text { virus infection }\end{array}$} \\
\hline Influenza A (\%) & $12(80)$ & $15^{b}$ \\
\hline Influenza B (\%) & $3(20)$ & $15^{b}$ \\
\hline Myoglobinuria & $9(56)$ & 16 \\
\hline \multicolumn{3}{|l|}{ Major complications } \\
\hline Rhabdomyolysis (\%) & $9(23)$ & $39 c$ \\
\hline Renal failure $(\%)$ & $8(21)$ & $39 c$ \\
\hline Compartment syndrome (\%) & $3(8)$ & $39 c$ \\
\hline Death & $1(3)$ & $39 c$ \\
\hline No complication (\%) & $28(72)$ & $39 c$ \\
\hline $\begin{array}{l}\text { Median duration to recovery } \\
\text { (days)[range] }\end{array}$ & $3[1-30]$ & 25 \\
\hline \multicolumn{3}{|c|}{$\begin{array}{l}\text { a interval between the onset of influenza-like illness and the on- } \\
\text { set of symptoms associated with IAM; b diagnosis was made by } \\
\text { serology and detection of virus in ten and five cases; }{ }^{c} \text { the total } \\
\text { number of complications listed exceeds the number of patients, } \\
\text { because some patients suffered from more than one complica- } \\
\text { tion }\end{array}$} \\
\hline
\end{tabular}

unspecific changes. Thus, muscle necrosis rather than myositis is the most common finding. In mild IAM, the muscle is mostly affected in a patchy pattern, contrasting with the more severe influenza-associated rhabdomyolysis, in which generalized necrosis may occur. Consequently, some authors have suggested that the term myopathy should be used, rather than myositis.

While epidemiologic, clinical and laboratory data establish a firm link between influenza virus infection and IAM, the mechanisms by which the virus leads to muscle involvement are poorly understood. The two most commonly proposed mechanisms are direct muscle invasion by viral particles and immune-mediated muscle damage triggered by the virus. The hypothesis of direct muscle invasion received support by findings of Bove et al. [37], who isolated the influenza virus from a muscle biopsy specimen in a child with IAM, and also by the reports of Gamboa et al. [38] and
Kessler et al. [39] who both isolated influenza virus from muscle specimens from adults with IAM. Additionally, Gamboa et al. [38] demonstrated myxovirus-like particles by muscle electron microscopy. Experimental studies [40-42] established that influenza virus is capable of infecting both animal and human muscle cells, with immature muscle cells being more permissive to infection than mature cells. This finding may explain the occurrence of IAM predominantly in children. A difference in muscle infectivity between influenza A and influenza B has not been established. Servidei et al. [42] proposed that a glycoprotein unique to influenza $\mathrm{B}$ may render the virus more myotropic than influenza A, but this hypothesis awaits experimental confirmation.

Immune mechanisms have not been investigated in detail. Early occurrence of IAM in the course of influenza and the absence of inflammatory infiltrates argue against an important role of an immune-mediated process. Risk factors for IAM brought forward in the literature include muscle tropism of specific influenza virus strains [35], male gender [35], and primary infection $[10,18,24,35]$ with an influenza virus.

The present compilation of cases draws a clear picture of the clinical presentation of IAM. It is a mostly benign complication, which mainly affects muscles of the lower extremities and appears when the symptoms of influenza are about to resolve. School-aged children are usually affected. Myalgia may be severe, appears with an abrupt onset and leads to gait abnormalities or refusal to walk for several days. Muscle swelling and tenderness may occur. An important differential diagnostic feature is the absence of neurological signs, although the reluctance of the child to use the painful extremity can mimic muscle weakness. Laboratory investigations should include blood CPK determination, which is almost invariably elevated, and virologic studies. Most alternative diagnoses can be readily excluded. Nonspecific myalgia is less severe and occurs at the climax of influenza infection. Guillain-Barré syndrome is associated with absent tendon reflexes. Arthritis is frequently asymmetric in distribution and CPK values are normal. Dermatomyositis is characterized by a subtle onset, chronic course and involvement of the skin. Deep venous thrombosis is an exceedingly rare condition in otherwise healthy children. It usually involves one extremity only and can be confirmed by Doppler sonography and determination of blood D-dimers.

If muscle pain, swelling, and tenderness worsen rapidly or the condition does not resolve within a few days, additional investigations of urine and renal parameters are indicated. If rhabdomyolysis occurs, inpatient monitoring is indicated for early recognition and treatment of complications such as acute renal failure, electrolyte disturbances, or compartment syndrome. Watanabe et al. [43] recently observed that rhabdomyolysis is the most frequently reported cause of renal injury in children with influenza A infection. Rhabdomyolysis has been reported more frequently in girls 
than in boys (4:1), and was mostly associated with influenza A infection. Thus, although influenza-associated rhabdomyolysis is rare, it should be considered in all patients with IAM and clinical follow-up should be ascertained.

\section{References}

1. Izurieta HS, Thompson WW, Kramarz P, Shay DK, Davis RL, DeStefano F, Black S, Shinefield H, Fukuda K: Influenza and the rates of hospitalization for respiratory disease among infants and young children. N Engl J Med 2000; 342: 232-239.

2. Neuzil KM, Mellen BG, Wright PF, Mitchel Jr EF, Griffin MR: The effect of influenza on hospitalizations, outpatient visits, and courses of antibiotics in children. N Engl J Med 2000; 342: 225-231.

3. Lundberg A: Myalgia cruris epidemica. Acta Paediatr 1957; 46: 18-31.

4. Middleton PJ, Alexander RM, Szymanski MT: Severe myositis during recovery from influenza. Lancet 1970; 2: 533-535.

5. Mejlszenkier JD, Safran AP, Healy JJ, Embree L, Ouellette EM: The myositis of influenza. Arch Neurol 1973; 29: 441-443.

6. Stevens D, Burman D, Clarke SK, Lamb RW, Hrper ME, Sarafian $\mathrm{AH}$ : Temporary paralysis in childhood after influenza B. Lancet 1974; 2: 1354-1356.

7. Barton LL, Chalhub EG: Letter: Myositis associated with influenza A infection. J Pediatr 1975; 87: 1003-1004.

8. Mason W, Keller E: Letter: Acute transient myositis with influenza-like illness. J Pediatr 1975; 86: 813-814.

9. Cifuentes E, Norman ME, Schwartz MW, Maley B, Bason W: Myoglobinuria with acute renal failure in children. The importance of intensive care and peritoneal dialysis. Clin Pediatr (Phila) $1976 ; 15: 63-66$.

10. Dietzman DE, Schaller JG, Ray CG, Reed ME: Acute myositis associated with influenza B infection. Pediatrics 1976; 57: 255--258.

11. McKinlay IA, Mitchell I: Transient acute myositis in childhood. Arch Dis Child 1976; 51: 135-137.

12. Baska RE, Frost MD: Acute postinfectious crural myalgia in children. South Med J 1977; 70: 419-420.

13. Buchta RM: Myositis and influenza. Pediatrics 1977; 60: 761-762.

14. DiBona FJ, Morens DM: Rhabdomyolysis associated with influenza A. Report of a case with unusual fluid and electrolyte abnormalities. J Pediatr 1977; 91: 943-945.

15. Tepperberg J: Transient acute myositis in children. JAMA 1977; 238: $27-28$.

16. Antony JH, Procopis PG, Ouvrier RA: Benign acute childhood myositis. Neurology 1979; 29: 1068-1071.

17. Farrell MK, Partin JC, Bove KE: Epidemic influenza myopathy in Cincinnati in 1977. J Pediatr 1980; 96: 545-551.

18. Ruff RL, Secrist D: Viral studies in benign acute childhood myositis. Arch Neurol 1982; 39: 261-263.

19. O'Reilly C, Gill D, Dockeray S: Acute transient myositis of childhood. Ir J Med Sci 1983; 152: 387-389.

20. Lai PC, Leung AK: Transient childhood myositis. Med J Aust 1985; 143: 222.

21. Mass A: Severe influenza myositis. Med J Aust 1985; 142: 330-331.

22. Robin $M$, Benichou JJ, Labrune B: [Acute influenzal myositis]. Arch Fr Pediatr 1986; 43: 666.
23. Kelly KJ, Garland JS, Tang TT, Shug AL, Chusid MJ: Fatal rhabdomyolysis following influenza infection in a girl with familial carnitine palmityl transferase deficiency. Pediatrics 1989; 84: 312-316.

24. Stang $\mathrm{H}$ : Acute transient myositis associated with influenza virus infection. Pediatr Infect Dis J 1989; 8: 257--258.

25 Christenson JC, San Joaquin VH: Influenza-associated rhabdomyolysis in a child. Pediatr Infect Dis J 1990; 9: 60--61.

26. Turner EA, Thompson HD, Reddy CM, South MA, Garrett-Ellis BR, Mirkovic RR: Sickle cell disease with complicated influenza B virus infection. J Natl Med Assoc 1992; 84: 524-527.

27. Paletta CE, Lynch R, Knutsen AP: Rhabdomyolysis and lower extremity compartment syndrome due to influenza B virus. Ann Plast Surg 1993; 30: 272-273.

28. Marquardt J, Selke T: Akute virale Myositis im Kindesalter. pädiat prax 1994; 48: 61-65.

29. Karpathios T, Kostaki M, Drakonaki S, Garoufi A, Siahanidou S, Spirou N, Theodoridis C: An epidemic with influenza B virus causing benign acute myositis in ten boys and two girls. Eur J Pediatr 1995; 154: 334-336.

30. McIntyre PG, Doherty C: Acute benign myositis during childhood: report of five cases. Clin Infect Dis 1995; 20: 722.

31. Dell KM, Schulman SL: Rhabdomyolysis and acute renal failure in a child with influenza A infection. Pediatr Nephrol 1997; 11: $363-365$.

32. Goebel J, Harter HR, Boineau FG, el Dahr SS: Acute renal failure from rhabdomyolysis following influenza $A$ in a child. Clin Pediatr (Phila) 1997; 36: 479-481.

33. Watanabe T, Oda Y: Rhabdomyolysis and acute renal failure in acute necrotizing encephalopathy with influenza A. Pediatr Nephrol 1998; 12: 85 .

34. Mackay MT, Kornberg AJ, Shield LK, Dennett X: Benign acute childhood myositis: laboratory and clinical features. Neurology 1999; 53: 2127-2131.

35. Moulin F, Mimieux C, Marc E, Gendrel D: [Post-influenza acute myositis]. Arch Pediatr 2000; 7 (Suppl. 3): 483-485.

36. Swaringen JC, Seiler JG, III, Bruce RW, Jr.: Influenza A induced rhabdomyolysis resulting in extensive compartment syndrome. Clin Orthop 2000; 243-249.

37. Bove KE, Hilton PK, Partin J, Farrell MK: Morphology of acute myopathy associated with influenza B infection. Pediatr Pathol 1983; 1: 51-66.

38. Gamboa ET, Eastwood AB, Hays AP, Maxwell J, Penn AS: Isolation of influenza virus from muscle in myoglobinuric polymyositis. Neurology 1979; 29: 1323-1335.

39. Kessler HA, Trenholme GM, Harris AA, Levin S: Acute myopathy associated with influenza $A / T e x a s / 1 / 77$ infection. Isolation of virus from a muscle biopsy specimen. JAMA 1980: 461-462.

40. Davis LE, Kornfeld M: Experimental influenza B viral myositis. J Neurol Sci 2001; 187: 61-67.

41. Inokuchi T, Hiromatsu Y, Ishii K, Kasho T, Abe T, Goto T, Kaji M: Myositis induced by influenza A in mice. Kurume Med J 1984; 31: 209-216.

42. Servidei S, Miranda AF, Gamboa ET: Infectivity of influenza B virus in cultured human muscle. Acta Neuropathol (Berl) 1987; 73: 67-76.

43. Watanabe T, Yoshikawa H, Abe Y, Yamazaki S, Uehara Y, Abe T: Renal involvement in children with influenza A virus infection. Pediatr Nephrol 2003; 18: 541-544. 